\title{
Inventário de Habilidades Sociais para Adolescentes (I HSA-Del-Prette): manual de aplicação, apuração e interpretação
}

\section{Josiane Rosa Campos*}

Universidade Federal de São Carlos - UFSCAR, São Carlos, SP, Brasil

DEL PRETTE, Almir; DEL PRETTE, Zilda Aparecida Pereira. I nventário de Habilidades Sociais para Adolescentes (IHSA-Del-Prette): manual de aplicação, apuração e interpretação. São Paulo: Casa do Psicólogo, 2009, 77p.

O desempenho social do adolescente vem sendo tema de interesse renovado nos últimos anos por parte de profissionais da saúde, educação, trabalho e mais recentemente dos psicólogos forenses. Sabe-se que a população adolescente é considerada uma população vulnerável a engajar-se em condições de risco, tais como, violência, abuso de drogas, gravidez indesejada, evasão escolar, que, por sua vez, favorecem a comportamentos de risco e desenvolvimento de diversos transtornos psicológicos (KAZDIN, 1993; 2000; MATOS, 2008). Por outro lado, muitos adolescentes estão submetidos às mesmas condições de risco e, no entanto, engajam-se em tarefas construtivas, envolvem-se atividades escolares, praticam esportes, apresentam um desenvolvimento saudável. Estas duas situações propiciam uma reflexão de que os adolescentes apresentam padrões de comportamentos diferenciados. Dentre estes padrões, destacamse os padrões sociais de interação, haja vista que os jovens passam a maior parte do tempo relacionando-se com os pares, família e professores. No entanto, ainda não é claro qual o padrão social apresentado pelos adolescentes, nos mais diversos contextos. Dessa maneira, pesquisas de caracterização desse repertório, que podem ser associadas a outras de caráter diagnóstico, podem ser fundamentais para subsidiar programas, ações e política pública de prevenção.

Uma questão levantada, nesse contexto de preocupações, é a da efetividade dos serviços prestados (DEL PRETTE; DEL PRETTE, 2008). Isto significa dizer que, não basta prestar o serviço, é necessário que seja avaliado em sua validade interna e externa. Práticas avaliativas confiáveis estão sendo cada vez mais exigidas, tanto por parte dos profissionais que prestam os serviços quanto pela clientela atendida (DEL PRETTE; DEL PRETTE, 2008). 
No entanto, ainda não se tem um levantamento amplo sobre quais são os desempenhos sociais dos adolescentes, no contexto brasileiro (DEL PRETTE; DEL PRETTE, 2009). Um dos prováveis motivos para a falta de pesquisas dessa natureza é a escassez de instrumentos confiáveis para a avaliação. Uma maneira de alcançar esse objetivo seria a construção de instrumentos com medidas psicométricas confiáveis para que os padrões sociais de interação do adolescente fossem mensurados. Um encaminhamento nessa direção foi realizado por Almir Del Prette e Zilda A. P. Del Prette, no campo teórico das Habilidades Sociais. Um investimento de pesquisa ao longo de quatro anos resultou na produção do Inventário de Habilidades Sociais para Adolescentes (IHSA-Del Prette).

O IHSA-Del Prette é um instrumento de autorrelato, de fácil aplicação e interpretação, com características psicométricas satisfatórias e recomendado pelo Conselho Federal de Psicologia. O instrumento focaliza uma série de demandas sociais fundamentadas nos conceitos do campo das Habilidades Sociais (DEL PRETTE; DEL PRETTE, 2005). As demandas sociais estão agrupadas em 38 itens de uma escala que produziu uma estrutura fatorial de seis subescalas. O IHSA-Del-Prette é apresentado em um kit de madeira contendo os materiais de aplicação e um manual. O manual é composto por seis seções e um apêndice. A seguir, será descrita, de forma sucinta, cada uma dessas seções.

A primeira seção, denominada Fundamentação teórica e empírica, consiste na exposição dos principais conceitos da área de Habilidades Sociais. Os autores tiveram dois objetivos: o primeiro deles foi permitir ao usuário o acesso a um conhecimento mínimo deste campo teórico que, posteriormente, seria requerido na interpretação dos resultados; o segundo objetivo foi explicitar ao leitor os conceitos norteadores que fundamentaram a construção do instrumento, o que é uma prática considerada importante em psicometria. Os conceitos centrais da área, abordados nesta seção, são: habilidades sociais, desempenho social, competência social, assertividade, automonitoria e demanda social (DEL PRETTE; DEL PRETTE, 2001). Há uma explanação também sobre as principais premissas do campo teórico das Habilidades Sociais.

Nessa parte, ainda, são apresentadas as principais demandas sociais vivenciadas por crianças e adolescentes e as classes e subclasses de habilidades sociais relevantes requeridas diante dessas demandas. Os autores fazem referências às classes de habilidades sociais propostas em outra obra (DEL PRETTE; DEL PRETTE, 2005): Autocontrole e expressividade emocional, Civilidade, Empatia, Assertividade, Fazer amizades, Solução de problemas interpessoais e Habilidades sociais acadêmicas. Cada uma dessas classes é apresentada também com suas subclasses, como por exemplo, a classe Empatia envolve que o adolescente observe o outro, preste atenção, infira sentimentos 
alheios, ofereça ajuda, saiba expressar sentimentos e, assim, ocorre sucessivamente com outras classes de habilidades sociais.

Posteriormente, e ainda na primeira seção, os autores contextualizam a importância do desenvolvimento das habilidades sociais na população adolescente, e as implicações da presença do repertório, enquanto fator de proteção e da ausência ou déficit, enquanto fator de risco. Finalizam essa parte discriminando os diferentes contextos a que os adolescentes estão submetidos e explanam sobre a necessidade da avaliação para fins preventivos e de tratamento.

Na segunda seção do manual, nomeada de Descrição do IHSA-DelPrette, os autores apresentam o inventário, provendo informações sobre a faixa etária de utilização, objetivos da aplicação, forma e tempo de aplicação, padronização, os contextos em que o instrumento pode ser utilizado e os campos de atuação da Psicologia em que pode ser aplicado bem como os principais indicadores psicométricos de validade e confiabilidade. Nessa parte, os autores também descrevem os dois indicadores produzidos pelo instrumento: freqüência e dificuldade.

Na terceira seção, denominada de Aplicação, os autores explicitam, de maneira clara e detalhada, as instruções de aplicação com recomendações normativas para uma aplicação adequada.

As informações contidas na quarta seção do manual, Apuração dos resultados, permitem que o usuário compreenda e execute a tabulação do escore geral e dos escores de cada subescala, e a conversão destes em posição percentil do respondente. Estas informações oferecem condições para uma análise detalhada do repertório de déficits e recursos de habilidades sociais do adolescente sendo possível traçar o perfil do respondente.

Cabe apontar que as instruções oferecidas, passo a passo no manual, são específicas para a apuração manual. O IHSA-Del-Prette oferece também a possibilidade da apuração informatizada dos resultados a partir do cadastramento do usuário junto à Editora. Importante ressaltar que as normas de referência foram estabelecidas por faixa etária correspondente a 12-13-14 anos e 15-16-17 anos, para os respondentes do sexo feminino e masculino e são apresentadas em quatro tabelas descritivas para o escore geral e para cada subescala. $\mathrm{Na}$ quinta seção, chamada de Interpretação dos resultados, os autores apresentam as classes de habilidades sociais derivadas da análise fatorial do instrumento e que foram organizadas em seis subescalas, a saber: Empatia, Autocontrole, Civilidade, Assertividade, Abordagem afetiva e Desenvoltura social. Os autores descrevem, detalhadamente, os comportamentos sociais correspondentes aos itens de cada uma dessas subescalas. Seguem apresentando as instruções para a interpretação dos escores totais e das subescalas com base na posição do percentil do respondente, comparativamente ao grupo de referência do mesmo sexo e faixa etária, tanto para o 
indicador de frequência quanto para o indicador de dificuldade. Nas tabelas também constam dados de média e desvio padrão de cada item do IHSA-Del-Prette, de modo que é possível analisar os itens específicos de habilidades sociais presentes ou ausentes no repertório do adolescente, o que permite uma análise ainda mais detalhada que auxilia no planejamento de intervenções que podem ser conduzidas de maneira individual ou grupal, em diversos contextos: clínica, educacional, organizacional e comunitário. Ainda, nessa parte do manual, os autores destacam algumas implicações da interpretação e finalizam com a ilustração de dois estudos de caso, o que facilita a compreensão do usuário sobre como interpretar os resultados obtidos.

Na última seção, denominada Estudos sobre o IHSA-Del-Prette, os autores versam sobre as propriedades psicométricas do instrumento, de maneira detalhada. Assim, são apresentados e discutidos os dados sobre o grupo amostral (características sociodemográficas, tamanho da amostra, distribuição dos escores com base no indicador de freqüência e dificuldade); os resultados obtidos a partir dos procedimentos utilizados para a análise dos itens; os estudos de validade baseadas nas evidências de conteúdo e domínio, estrutura fatorial, consistência interna, relação com as mudanças desenvolvimentais e relação com outras variáveis foram explicitados. Esta seção é finalizada com a descrição de uma síntese do propósito da aplicação do instrumento a diferentes contextos e das evidências de validade, tais como: estabilidade temporal (teste-reteste), consistência interna dos itens, correlação entre as formas paralelas. Nos estudos apresentados, há evidências de propriedades psicométricas bastantes favoráveis ao IHSA-Del-Prette em termos da validade e da confiabilidade do instrumento.

O Inventário de Habilidades Sociais para Adolescentes IHSA-DelPrette representa uma contribuição relevante tanto para o campo das Habilidades Sociais como para a área da avaliação psicológica, no contexto brasileiro. A obra resenhada apresenta fundamentos consistentes e detalhamento teórico e técnico que embasaram a construção do instrumento. Consequentemente, isto implica em um ganho metodológico aos pesquisadores que pretendem iniciar estudos sobre desempenho social de adolescentes de diversos contextos, inclusive com amostras clínicas e subclínicas, de distintas regiões do país. Além disso, a disponibilização desse instrumento no mercado pode auxiliar na qualificação dos serviços prestados por profissionais habilitados a utilizá-lo.

\section{Referências Bibliográficas}

DEL PRETTE, A.; DEL PRETTE, Z. Psicologia das Relações Interpessoais: vivências para o trabalho em grupo. Petrópolis: Vozes, 2001. 
prática. Petrópolis: Vozes, 2005.

Psicologia das Habilidades Sociais na infância: teórica e Significância clínica e mudança confiável na avaliação de intervenções psicológicas. Psicologia: Teoria e Pesquisa, Brasília, v. 24, n. 4, p. 497-505, out-dez 2008.

- Inventário de Habilidades Sociais para Adolescentes (IHSA-Del-Prette): manual de aplicação, apuração e interpretação. São Paulo: Casa do Psicólogo, 2009.

- Adolescência e fatores de risco: a importância das habilidades sociais educativas. In: HAASE, V. G.; FERREIRA, F. O.; PENNA, F. J. (Orgs.). Aspectos biopsicossociais da saúde na infância e adolescência. Belo Horizonte: Coopmed, 2009, p. 503522.

KAZDIN, A. E. Adolescent mental health: Prevention and treatment programs. American Psychologist, Washington, v. 48, p. 127-141, 1993.

. Psychoterapy for children and adolescents: directions for research and practice. Oxford: Oxford University Press, 2000.

MATOS, M. G. Sexualidade, Segurança \& SIDA: estado da arte e propostas em meio escolar. Cruz Quebrada: Aventura Social e Saúde, 2008.

\section{Endereço para correspondência}

Josiane Rosa Campos

Laboratório de Interação Social (LIS), Grupo Relações Interpessoais e Habilidades Sociais (RIHS), Rodovia Washington Luiz, Km 235, CEP 13565-905, São Carlos-SP, Brasil

Endereço eletrônico: josircampos@hotmail.com

Recebido em: 27/07/2010

Aceito para publicação em: 28/07/2010

Acompanhamento do processo editorial: Adriana Benevides Soares

\section{Notas}

* Doutoranda do Programa de pós-graduação em Psicologia da Universidade Federal de São Carlos - UFSCAR. 